\title{
PENGEMBANGAN DESAIN INTERIOR RUMAH KREATIF BATIK PUTAT JAYA UNTUK MENINGKATKAN KUALITAS HIDUP MASYARAKAT EKS LOKALISASI DOLLY
}

\author{
Timotius Andrew ${ }^{1}$, Christopher Wibisono ${ }^{2}$, Joshua Sasongko ${ }^{3}$, Mariana Wibowo ${ }^{4 *}$ \\ 1,2,3,4 Program Studi Desain Interior, Universitas Kristen Petra \\ Jl. Siwalankerto 121-131, Surabaya \\ *Penulis korespondensi; Email: Mariana_wibowo@petra.ac.id
}

\begin{abstract}
Abstrak: Kelurahan Putat Jaya, Surabaya merupakan kawasan Eks-Lokalisasi Dolly yang dikenal dengan masa lalunya yang banyak dilakukan praktek prostitusi. Untuk memperbaiki citra negatif yang muncul, pemerintah telah menyediakan beberapa program untuk memperbaiki kualitas hidup masyarakat di kawasan Dolly, salah satunya ialah Rumah Kreatif Batik Putat Jaya, yang difungsikan sebagai fasilitas pelatihan dalam melestarikan budaya batik. Guna meningkatkan kualitas pelatihan dan kesadaran masyarakat terhadap fasilitas tersebut, maka dilakukan pengembangan desain interior Rumah Kreatif Batik Putat Jaya. Kegiatan pengembangan desain interior ini dilakukan oleh lima orang Mahasiswa, dan dibimbing oleh satu dosen dari Program Studi Desain Interior Universitas Kristen Petra. Metode desain yang digunakan melalui lima tahapan Design Thinking menurut Stanford, yaitu emphatize, define, ideate, prototype, dan test. Proyek pengabdian masyarakat ini menghasilkan desain interior dengan konsep fun, yang berhasil meningkatkan kualitas pelatihan di Rumah Kreatif Batik Putat Jaya.
\end{abstract}

Kata kunci: Interior; rumah kreatif; batik; Surabaya.

\begin{abstract}
Putat Jaya, Surabaya is a Dolly Ex-Localization area, known for its past, which is widely practiced with prostitution. To improve the negative image that has emerged, the government has provided several programs to improve the quality of life of the people in the Dolly region, one of which is the Putat Jaya Batik Creative House, which functions as a training facility in preserving batik culture. In order to improve the quality of training and public awareness of these facilities, an interior design development for the Putat Jaya Batik Creative House was carried out. The interior design development activities were carried out by five students, and guided by one lecturer from the Petra Christian University Interior Design Study Program. Design methods are used through five stages of Design Thinking according to Stanford, namely emphatize, define, ideate, prototype, and test. This community service project produced an interior design with a fun concept, which succeeded in improving the quality of training at Putat Jaya Batik Creative Home.
\end{abstract}

Keywords: Interior; creative home; batik; Surabaya.

\section{PENDAHULUAN}

Prostitusi di Indonesia merupakan salah satu kegiatan illegal yang seringkali ditemui di kehidupan dunia malam. Kota Surabaya juga terkenal dengan kawasan prostitusi yang bersejarah dan telah berjalan selama puluhan tahun sejak tahun 1960, yaitu Dolly. Kawasan Dolly atau yang dikenal dengan sebutan "gang Dolly" ini merupakan area jalan sepanjang 200 meter. Lokalisasi Dolly merupakan kawasan lokalisasi terbesar se-Asia Tenggara, melebihi kawasan prostitusi di Bangkok, Thailand dan Gaylang, Singapore. (Atikah, 2015)

Pada tanggal 18 Juni 2014, deklarasi penutupan lokalisasi Dolly telah menimbulkan kontroversi, terutama bagi mereka yang memperoleh penghasilan dari kawasan tersebut, seperti para PSK dan mucikari, serta para pedagang, tukang ojek, atau tukang becak. Lokalisasi dianggap memberi penghidupan bagi masyarakat sekitar. Pemindahan pusat perekonomian dari satu tempat ke tempat lain akan menimbulkan ketakutan bagi pelaku usaha, terkait penghasilan yang akan didapat.

Pemerintah telah menciptakan Program Surabaya Bebas Prostitusi, untuk menanggulangi masalah sosial dan ekonomi yang muncul, di antaranya dengan membekali mereka kemampuan usaha dan ekonomi. Salah satu program pemerintah yang sedang berjalan yaitu, Rumah Kreatif Batik. Rumah Kreatif Batik ini berlokasi di Jalan Putat Jaya Barat VIII B, Surabaya. Melalui fasilitas yang disediakan ini, masyarakat yang dulunya bekerja sebagai pelaku prostitusi jadi memiliki kegiatan yang lebih produktif dan bermanfaat. (Retnaningsih,2014) 
Menyambut program pemerintah dalam meningkatkan produktivitas masyarakat, kami melakukan pengembangan terhadap desain eksisting Rumah Kreatif Batik yang dinilai masih kurang maksimal dalam menarik perhatian masyarakat. Hal ini disebabkan karena elemen interior yang kurang layak, yang meliputi: tidak adanya area untuk display batik, kurangnya penataan interior yang sesuai dengan kebutuhan aktivitas dalam pembuatan batik, menerima tamu, dan area workshop. Data permasalahan tersebut didapatkan dari kegiatan observasi dan wawancara terhadap pengelola Rumah Kreatif Batik.

Banyak peluang dalam karya batik yang telah dibuat oleh komunitas rumah batik putat jaya yang tidak tersampaikan dengan baik melalui desain eksisting bekas praktek lokalisasi Dolly. Akibatnya, apresiasi yang dimunculkan oleh masyarakat menjadi minim, yang menyebabkan perlambatan dalam pertumbuhan ekonomi disana.

Dengan pengembangan desain terhadap Rumah Kreatif Batik, diharapkan dapat menjadi sarana dalam mendukung program pemerintah, sekaligus meningkatkan kualitas hidup bagi masyarakat eks lokalisasi Dolly.

\section{Fungsi Galeri}

Menurut (Harjendro, 2004:37), fungsi galeri dibagi menjadi:

1. Sebagai tempat mengumpulkan hasil karya seni.

2. Sebagai tempat memamerkan hasil karya seni agar dikenal masyarakat.

3. Sebagai memelihara hasil karya seni agar tidak rusak.

4. Sebagai tempat mengajak/mendorong/meningkatkan apresiasi masyarakat.

5. Sebagai tempat transaksi jual beli untuk merangsang kelangsungan seni.

Jenis-jenis penataan gallery, dibagi menjadi tiga, yaitu:

\section{a. In Show Case}

Benda koleksi mempunyai dimensi kecil maka diperlukan suatu tempat display berupa kotak tembus pandang yang biasanya terbuat dari kaca. Selain untuk melindungi, kotak tersebut terkadang berfungsi untuk memperjelas atau memperkuat tema benda koleksi yang ada.

$b$. Free standing on the floor or plinth or supports

Benda yang akan dipamerkan memiliki dimensi yang besar sehingga diperlukan suatu panggung atau pembuatan ketinggian lantai sebagai batas dari display yang ada. Contoh: patung, produk instalasi seni, dan lain-lain.

c. On wall or panels

Benda yang akan dipamerkan biasanya merupakan karya seni 2 dimensi dan ditempatkan di dinding ruangan maupun partisi yang dibentuk untuk membatasi ruang. Contoh: karya seni lukis, karya fotografi, dll.

\section{Sistem Pencahayaan}

Menurut Keputusan Menteri Kesehatan No. 1405 tahun 2002, pencahayaan adalah jumlah penyinaran pada suatu bidang kerja yang diperlukan untuk melaksanakan kegiatan secara efektif. Dengan adanya cahaya pada lingkungan ruang dalam yang bertujuan menyinari berbagai bentuk elemen-elemen yang ada di dalam ruang, sehingga ruangan menjadi teramati dan dapat dirasakan suasana visualnya (Honggowidjaja, 2003).

Pencahayaan pada galeri memberikan kontribusi yang besar tentang bagaimana menampilkan benda yang dipamerkan agar lebih memiliki kekuatan dan menarik sesuai tema yang ada, selain itu pencahayaan juga dapat memberikan fokus yang lebih menonjol dibandingkan dengan suasana galeri secara keseluruhan. Berdasarkan sumber dan fungsinya pencahayaan dibagi menjadi:

a) Pencahayaan Alami (Natural Lighting)

b) Pencahayaan Buatan (General Artificial Lighting).

Sistem pencahayaan merupakan salah satu faktor penting yang harus dipertimbangkan dalam proses mendesain. Untuk menciptakan suasana yang diinginkan pada sebuah ruang, dibutuhkan jenis sistem pencahayaan dalam ruangan. Teknik pendistribusian cahaya, dibedakan menjadi:

- Direct Lighting

- Semi Direct Lighting

- General Difuse Lighting

- Semi Indirect Lighting

- Indirect Lighting

\section{Public Space}

Berdasarkan fungsinya, ruang publik dapat dibagi menjadi beberapa jenis (Carmona, et al: 2008, p.62), antara lain:

1. Positive space

Ruang ini berupa ruang publik yang dapat dimanfaatkan untuk kegiatan-kegiatan yang sifatnya positif dan biasanya dikelola oleh pemerintah. Bentuk dari ruang ini antara lain ruang alami/semi alami, ruang publik dan ruang terbuka publik.

\section{Negative space}

Ruang ini berupa ruang publik yang tidak dapat dimanfaatkan bagi kegiatan publik secara optimal karena memiliki fungsi yang tidak sesuai dengan kenyamanan dan keamanan aktivitas sosial serta kondisinya yang tidak dikelola dengan baik. Bentuk dari ruang ini antara lain ruang pergerakan, ruang servis dan ruang-ruang yang ditinggalkan karena kurang baiknya proses perencanaan. 


\section{Ambiguous space}

Ruang ini adalah ruang yang dipergunakan untuk aktivitas peralihan dari kegiatan utama warga yang biasanya berbentuk seperti ruang bersantai di pertokoan, café, rumah peribadatan, ruang rekreasi, dan lain sebagainya.

\section{METODE PELAKSANAAN}

Proses perancangan dengan metode design thinking dilakukan dengan tahapan berikut ini:

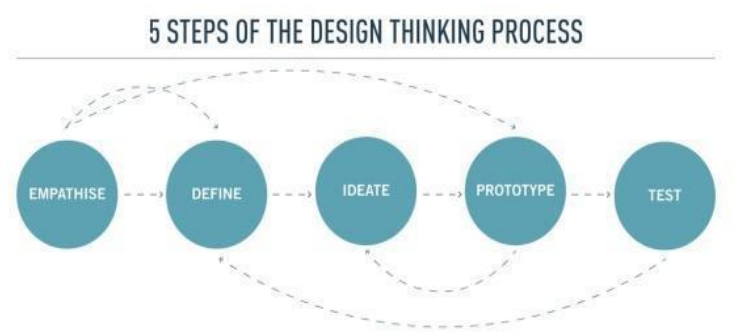

Gambar 1. Metode Design Thinking menurut Stanford

\section{Emphatize}

Tahap emphatize bertujuan untuk bisa merasakan kebutuhan pengguna, dengan cara mencoba untuk menempatkan diri sebagai pengguna (observasi). Pada tahap ini dilakukan eksplorasi data literatur dan data lapangan. Data literatur yang telah diperoleh berhubungan dengan desain rumah kreatif yang dapat meningkatkan dan men dukung aktivitas pengguna sehingga tetap nyaman dan ergonomis. Sedangkan data lapangan yang diperoleh dari lapangan existing yaitu Rumah Kreatif Batik Putat Jaya yang terletak di Jalan Putat Jaya Barat VIII B, Surabaya. Metode lain yang digunakan yaitu user interview. Di mana metode ini digunakan untuk mengetahui kebutuhan dan goals yang ingin dicapai oleh pengguna
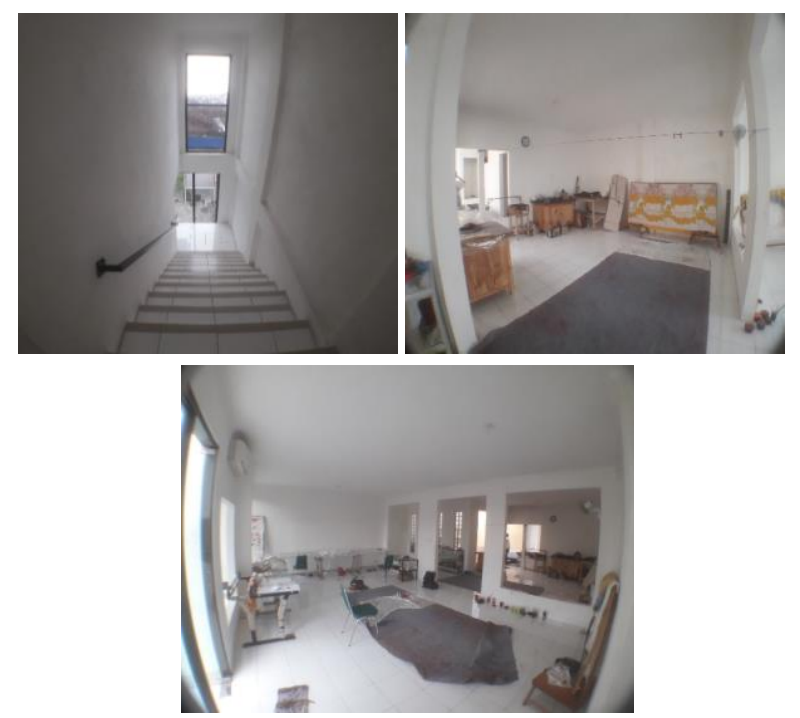

Gambar 2. Proses Dokumentasi

\section{Define}

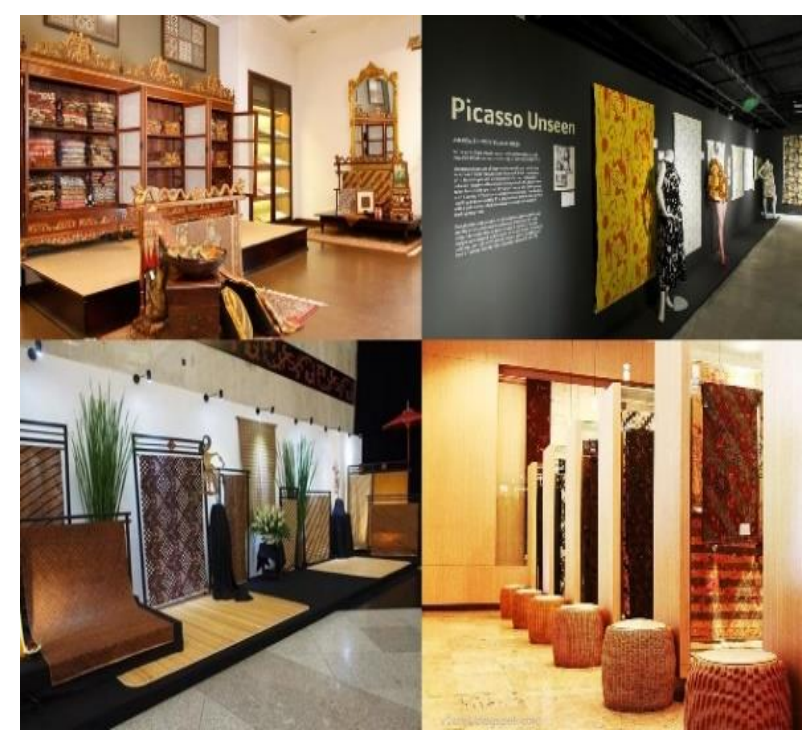

Gambar 3. Moodboard

Pada tahap ini dilakukan programming akan desain yang ingin direalisasikan dengan menggunakan framework untuk mengetahui permasalahan yang ada agar bisa diselesaikan melalui berbagai alternatif desain. Selain itu juga dibuat moodboard yang nantinya sebagai inspirasi dari desain yang akan dihasilkan.

\section{Ideate}

Pada tahap ideate ini dilakukan proses brainstorming ide-ide yang disesuaikan dengan hasil dari tahap emphatize dan define. Dilanjutkan dengan pembuatan sketsa mengenai hal yang ingin direalisasikan. Sketsa ini bertujuan untuk mendapatkan gambaran mengenai desain yang akan diterapkan nantinya. Dalam tahap ini, dilakukan brainstorming untuk mendapatkan ide-ide desain berdasar data yang telah terkumpul. Selanjutnya hasil desain yang telah dibuat dikonsultasikan dengan dosen pembimbing untuk mendapat kritik dan saran.

a. Konsep Desain

Rumah Kreatif Batik Putat Jaya ini dirancang dengan konsep fun menggunakan warna cerah yang dapat membangkitkan semangat dan menciptakan harmoni di dalam melakukan aktivitas yaitu warna orange dan hijau. Rumah batik ini dirancang dengan baik menggunakan nuansa modern yang dipadukan dengan sentuhan tradisional dari batik itu sendiri yang digunakan sebagai estetika di dalam ruangan. Oleh karena ini rumah batik ini difungsikan sebagai pameran batik dan juga sebagai tempat pelatihan batik bagi masyarakat umum yang ingin belajar mengenai cara pembuatan batik. 
b. Gaya dan Suasana Ruang

Nuansa yang ditampiklan pada Rumah Kreatif Batik Putat Jaya ini adalah nuansa modern dengan sentuhan tradisional dari batik. Menggunakan warna cerah yaitu warna orange yang mampu meningkatkan semangat seseorang di dalam melakukan aktivitasnya dan warna hijau yang mampu membuat seseorang tetap dapat relax dan merasa senang.

\section{Prototype}

Tahap ini dilakukan dengan cara mengimplementasikan ide dalam sebuah aplikasi atau produk uji coba. Tahap ini dilakukan dengan merealisasikan ide desain dengan pembuatan produk 1:1 dari alternatif yang terpilih. Dalam tahap ini, tim dibagi menjadi beberapa divisi, yaitu divisi lapangan, divisi sekretaris dan bendahara, dan divisi desain. Divisi lapangan bertugas untuk melakukan kontrol lapangan yaitu mengawasi dan menerima setiap barang yang dikirim, dan melakukan setting di lapangan. Divisi sekretaris dan bendahara bertugas untuk mencatat setiap progress yang sudah dilakukan dan juga mencatat segala pengeluaran untuk nantinya dibuat laporan pertanggung jawaban. Divisi desain bertugas menyiapkan segala macam gambar teknis yang nantinya dipakai untuk pelaksanaan di lapangan.

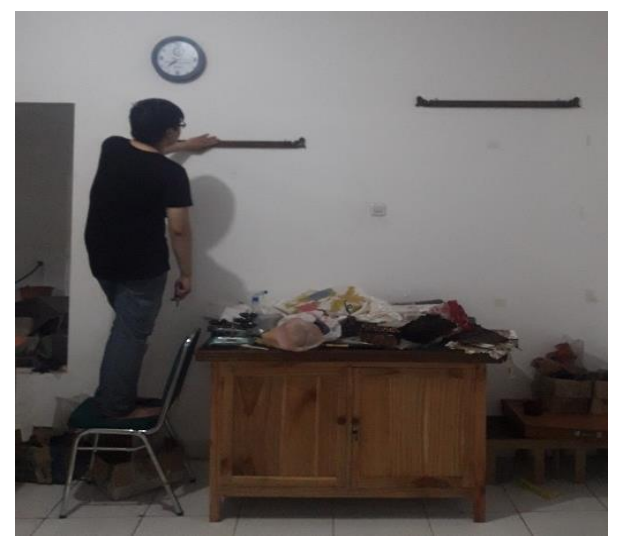

Gambar 4. Proses Pemasangan Hanger Batik

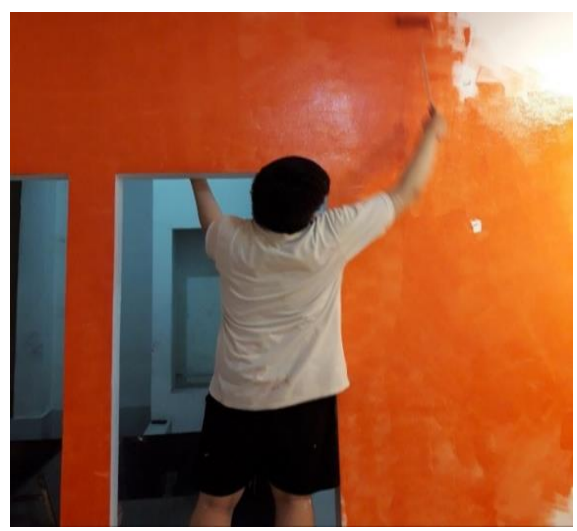

Gambar 5. Proses Pengecatan

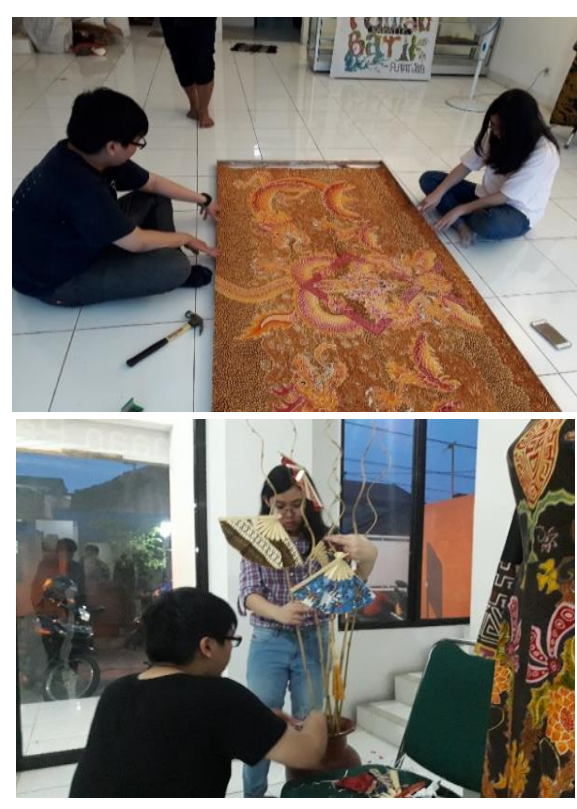

Gambar 6. Proses styling

a. Layout Objek Perancangan

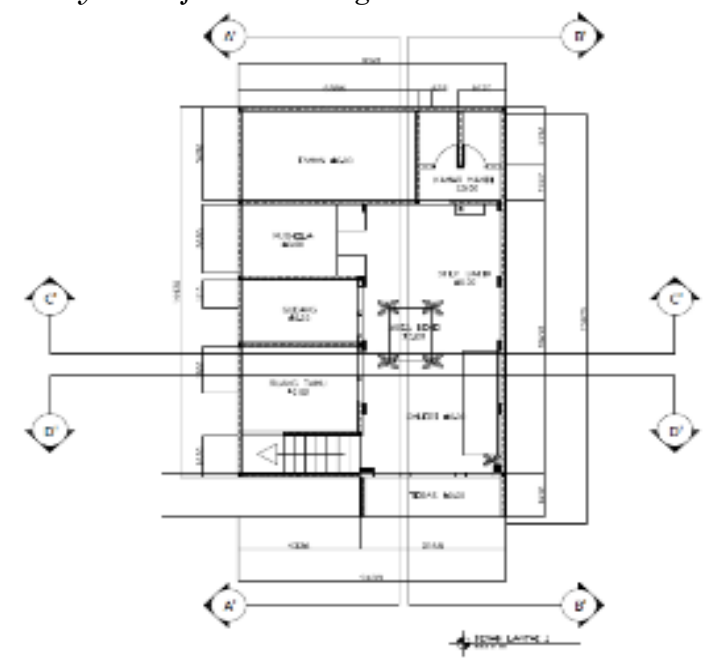

Gambar 7. Layout Lantai 1

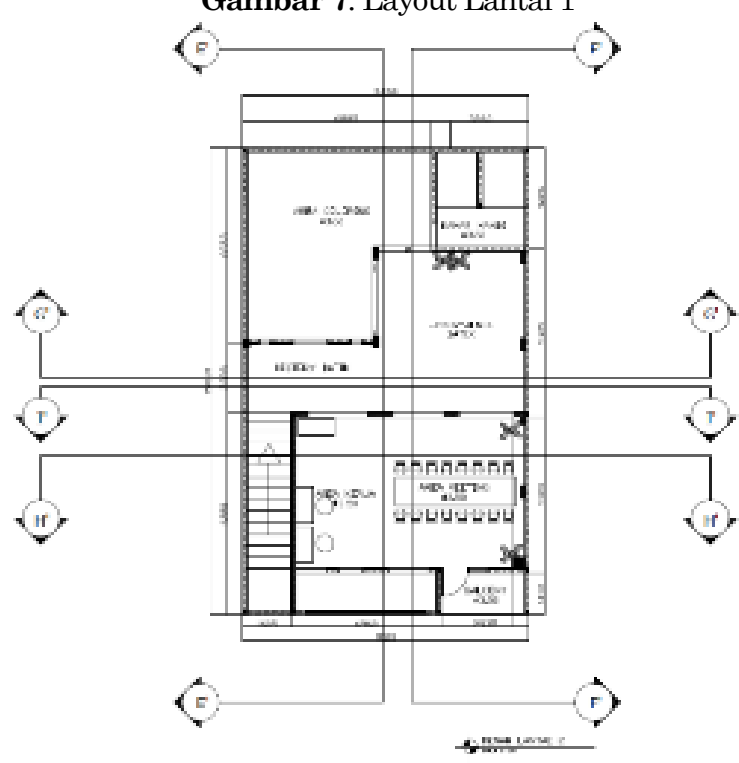

Gambar 8. Layout Lantai 2 
Tahap pertama yang dilalui dalam bangunan ini adalah main entrance yang terletak pada bagian depan bangunan. Kemudian setelah masuk di area lantai satu mengarah kepada area untuk galeri batik dan kemudian pada lantai dua merupakan tempat untuk pelatihan batik.

b. Tampak Potongan

Tampak potongan perancangan interior Rumah Batik Putat Jaya diperoleh dari berbagai sisi bangunan untuk dapat melihat desain dalam bentuk 2D. Berikut adalah tampak potongan perancangan Rumah Batik Putat Jaya, antara lain:

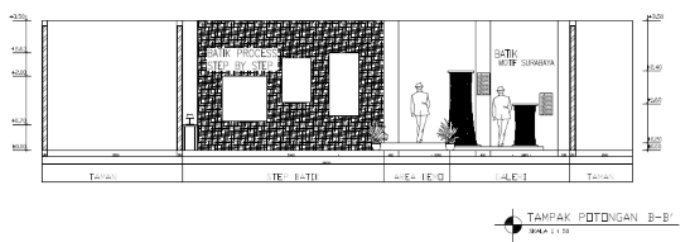

Gambar 9. Tampak Potongan A-A

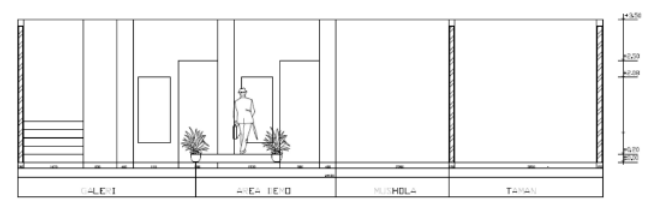

Gambar 10. Tampak Potongan B-B
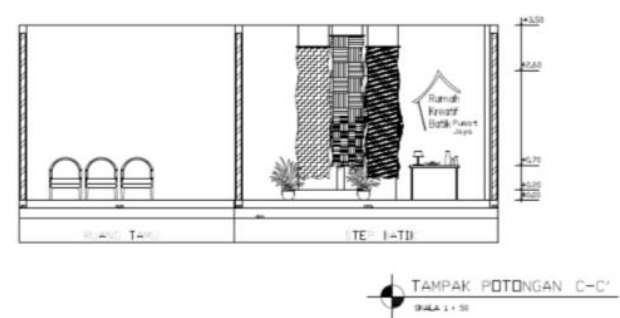

Gambar 11. Tampak Potongan C-C

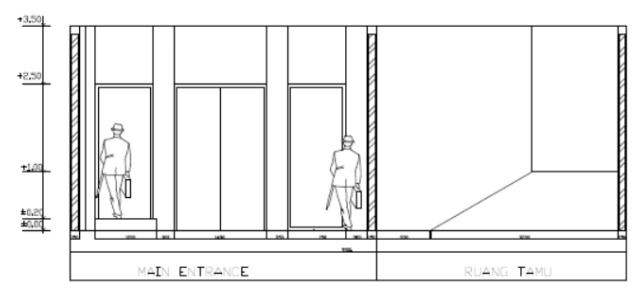

TAMPAK PQTENGAN D-D'

Gambar 12. Tampak Potongan D-D

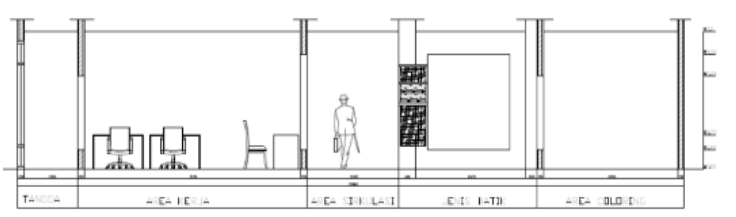

6 TAMPAK PDTONGAN E-E.

Gambar 13. Tampak Potongan E-E

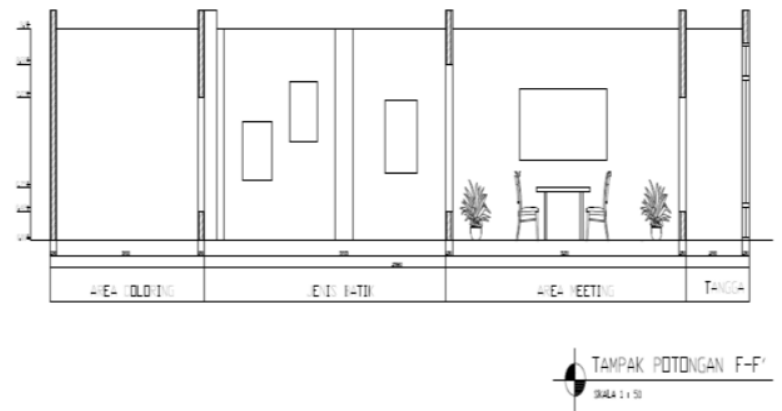

Gambar 14. Tampak Potongan F-F

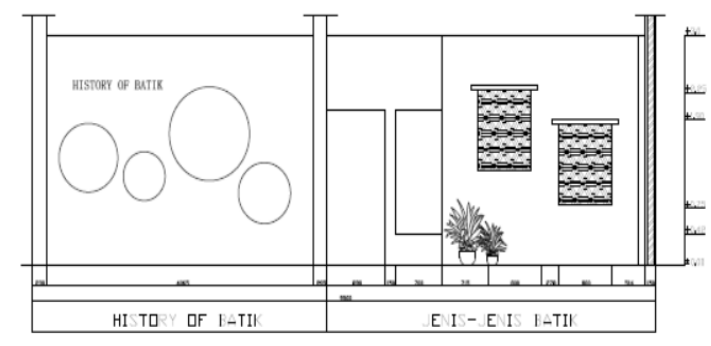

TAMPAK PQTLNGAN G-G'

Gambar 15. Tampak Potongan G-G

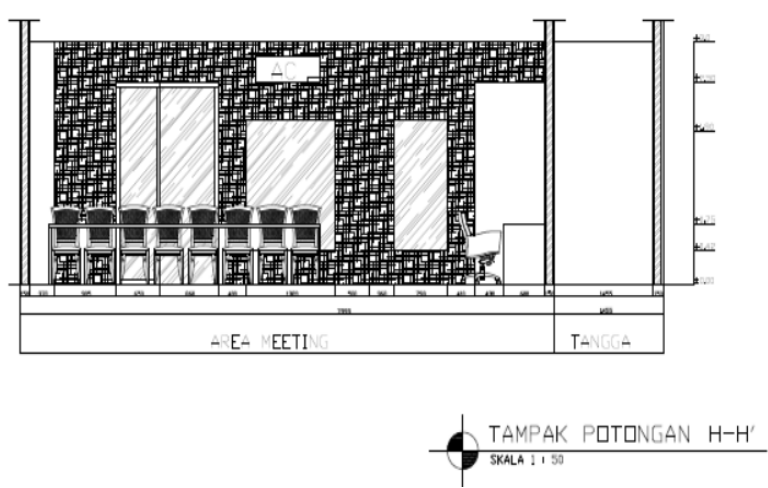

Gambar 16. Tampak Potongan H-H

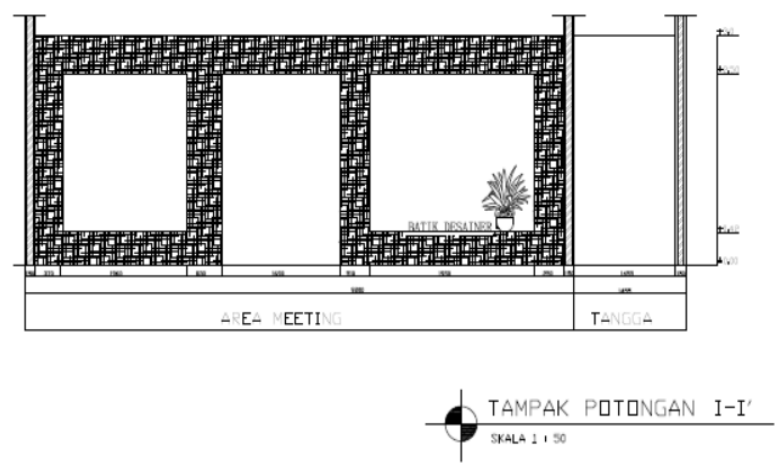

Gambar 17. Tampak Potongan I-I

c. Perspektif interior Rumah Batik Putat Jaya Area galeri merupakan tempat untuk menampilkan produk-produk batik yang merupakan hasil buatan pengelola rumah batik ini. Warna orange diterapkan pada elemen dinding. Di dalam menambah nilai estetika pada display batik juga digunakan lampu sorot pada display. 


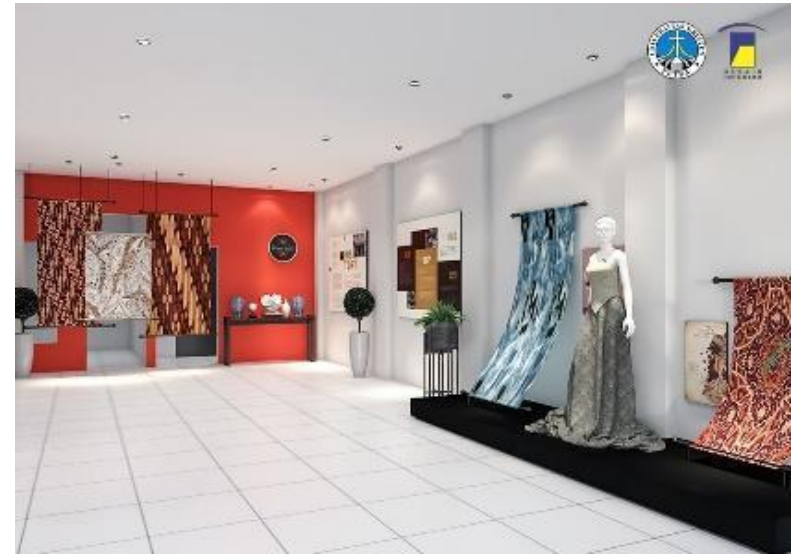

Gambar 18. Perancangan Area Galeri Rumah Batik Putat Jaya

Pada lorong di rumah batik ini juga menggunakan konsep warna hijau yang digunakan pada elemen dinding. Lorong ini berhubungan dengan area workshop.

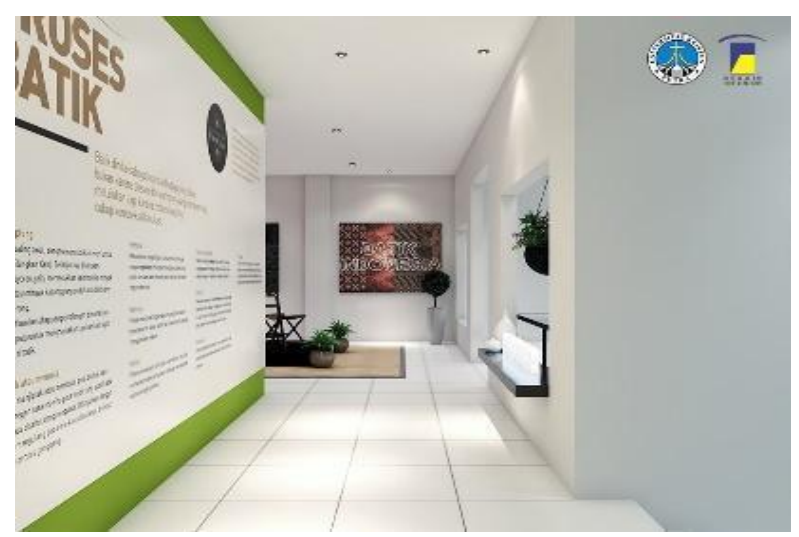

Gambar 19. Perancangan Lorong Sirkulasi Rumah Batik Putat Jaya

Area workshop ini digunakan oleh para pengelola dan masyarakat untuk pelatihan batik. Fasilitas yang tersedia berupa meja dan kursi untuk mendukung aktivitas.

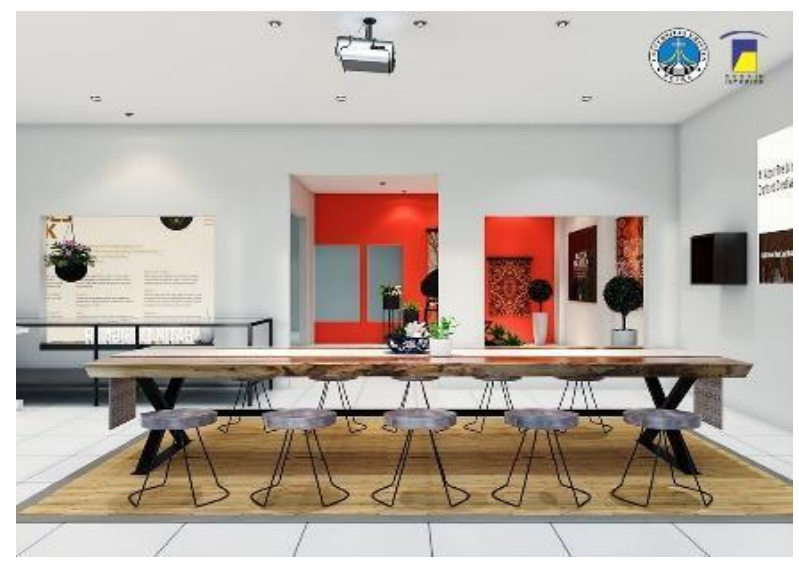

Gambar 20. Perancangan Area Workshop Rumah Batik Putat Jaya

\section{HASIL DAN PEMBAHASAN}

Gambar dibawah ini merupakan hasil realisasi di Rumah Batik Putat Jaya;

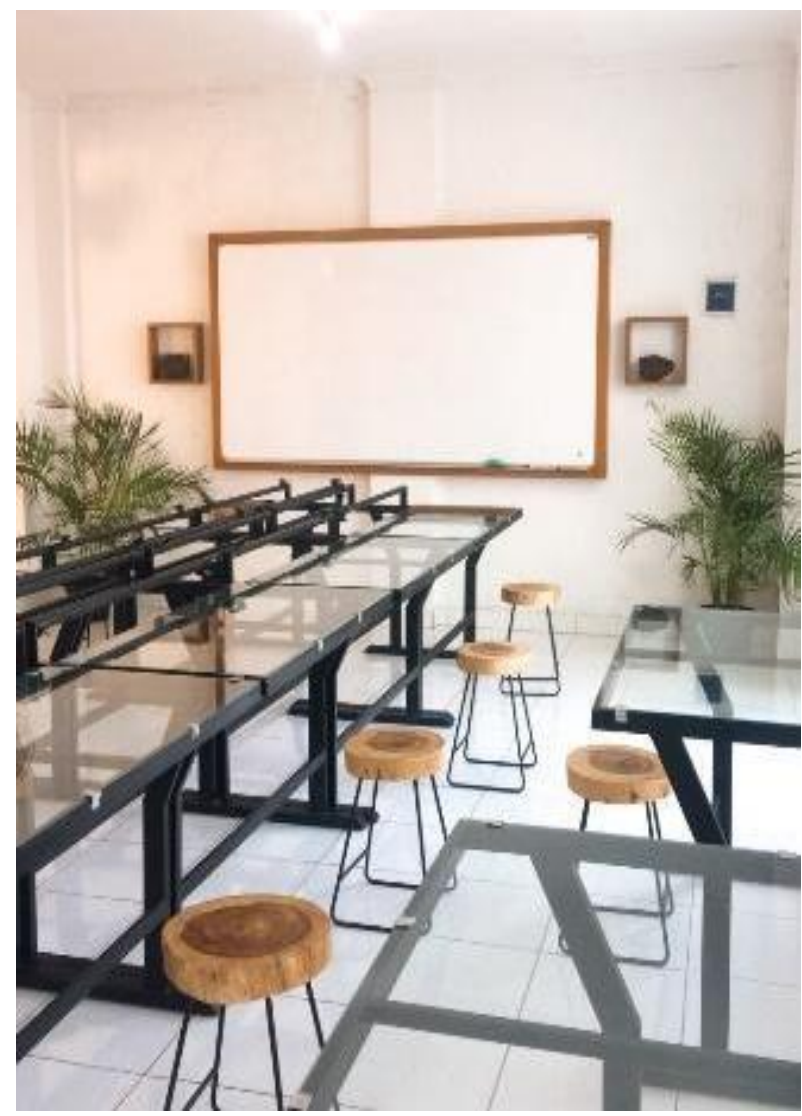

Gambar 21. Area Workshop Rumah Bati Putat Jaya

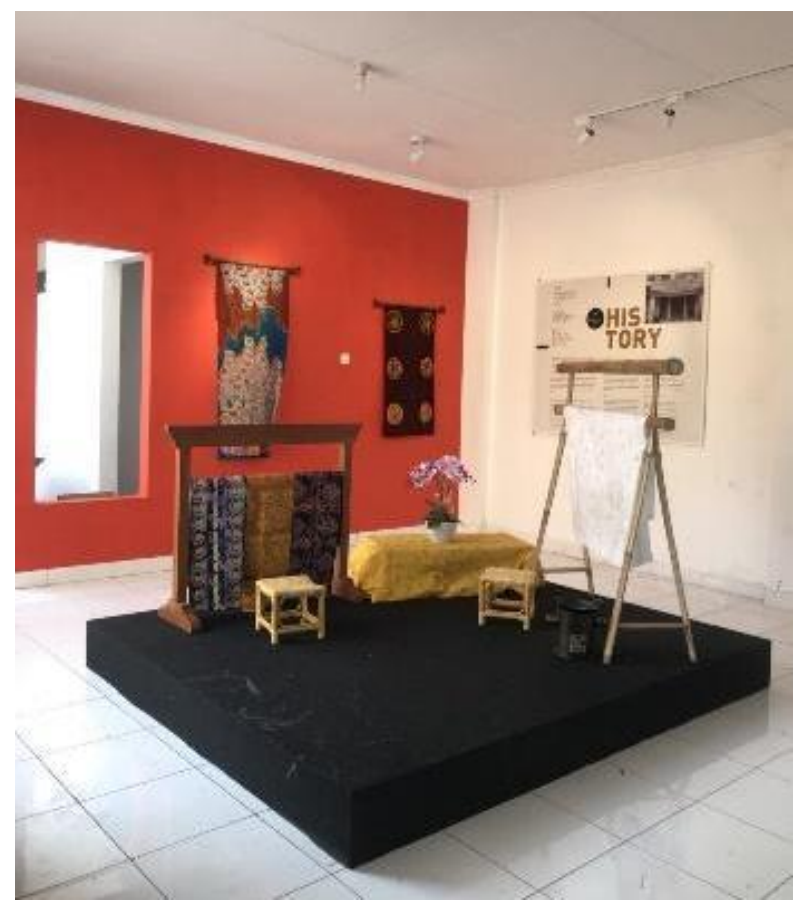

Gambar 22. Area Galeri Rumah Batik Putat Jaya 


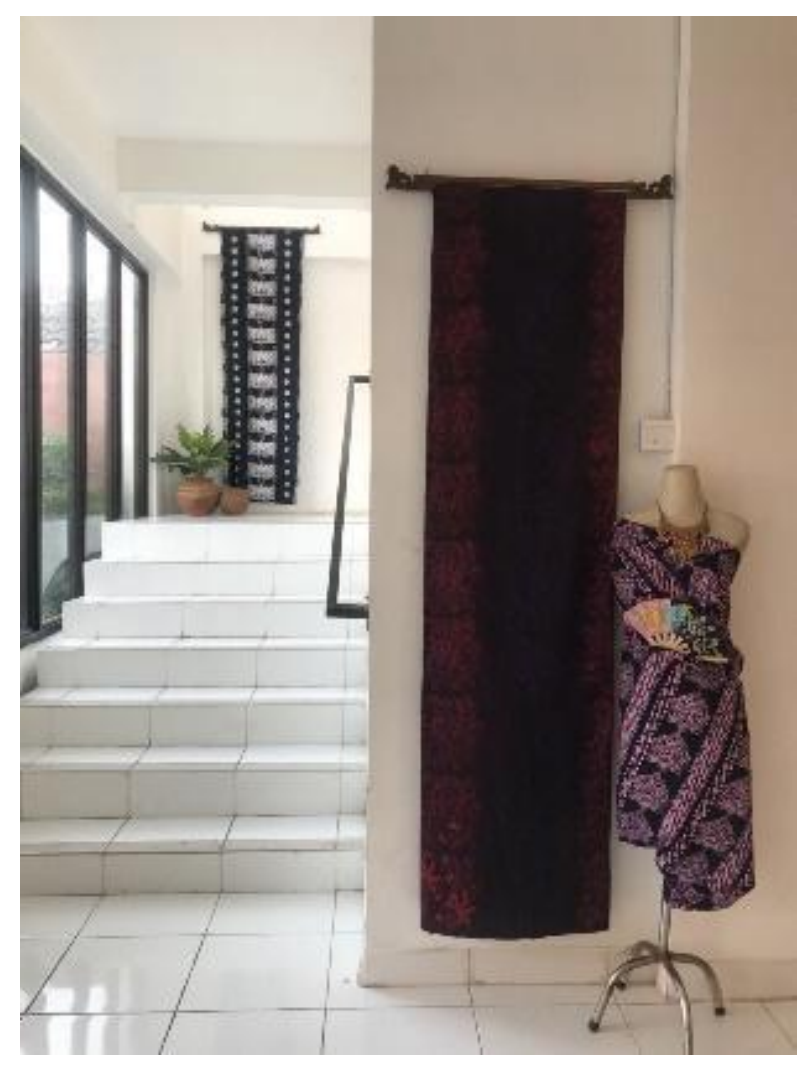

Gambar 23. Area Galeri Rumah Batik Putat Jaya

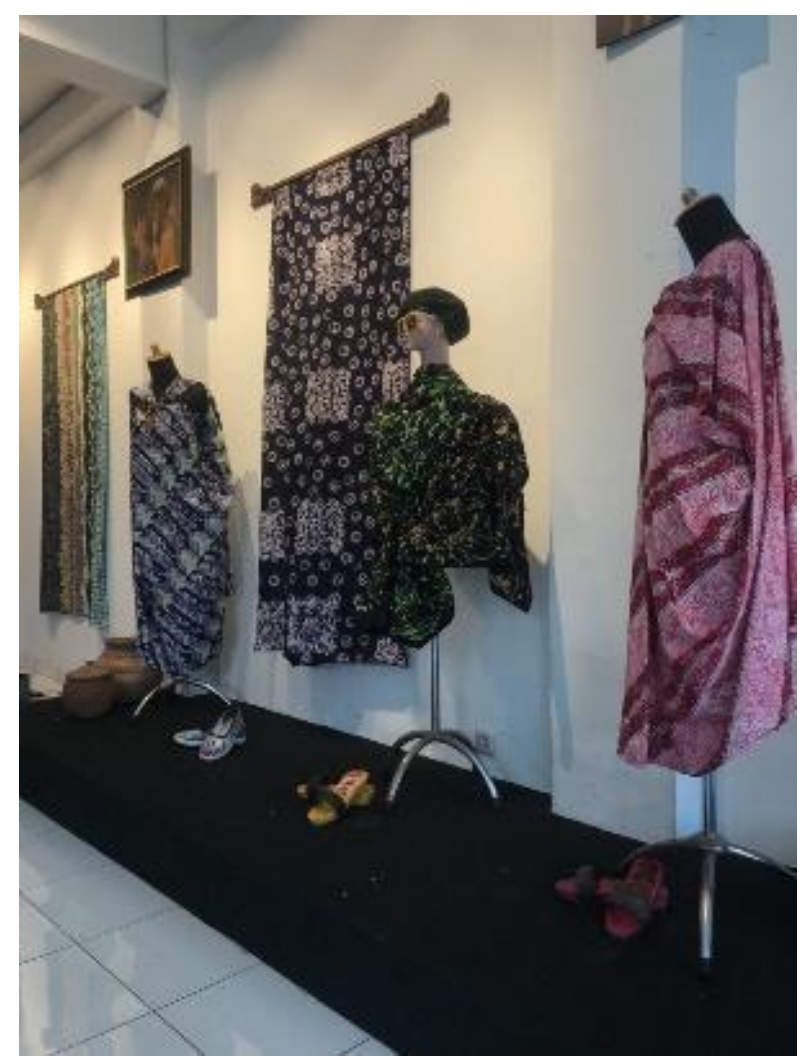

Gambar 24. Area Galeri Rumah Batik Putat Jaya

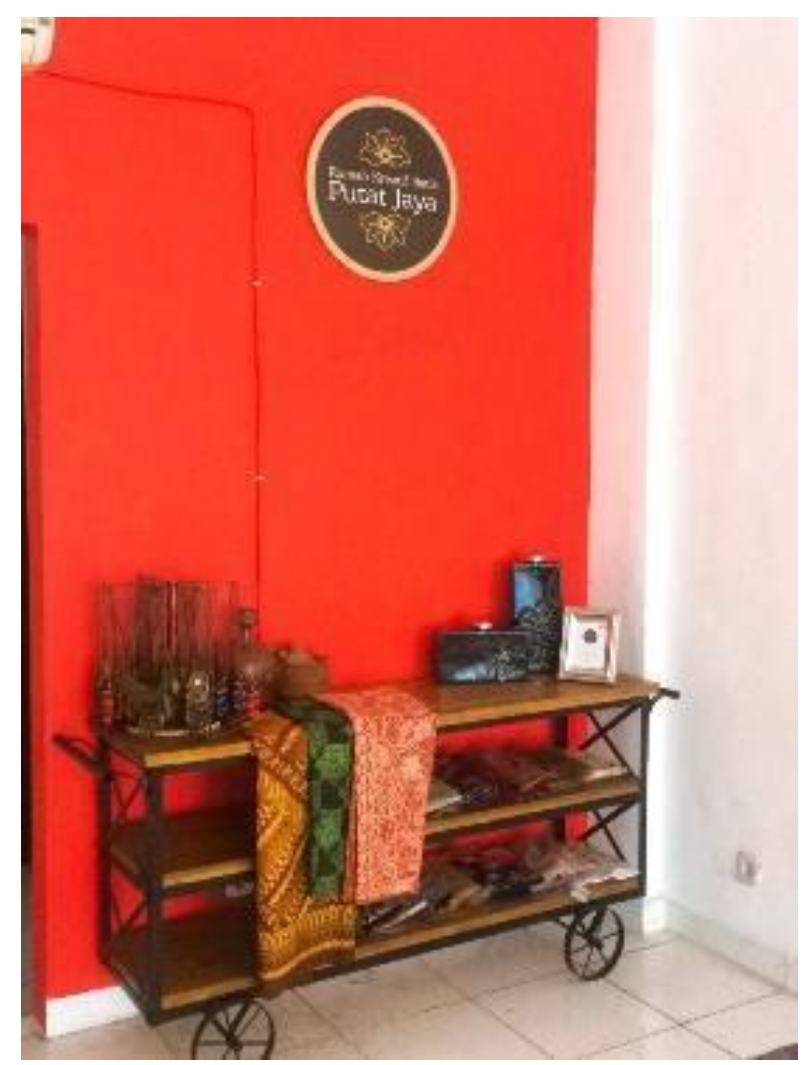

Gambar 25. Area Galeri Rumah Batik Putat Jaya

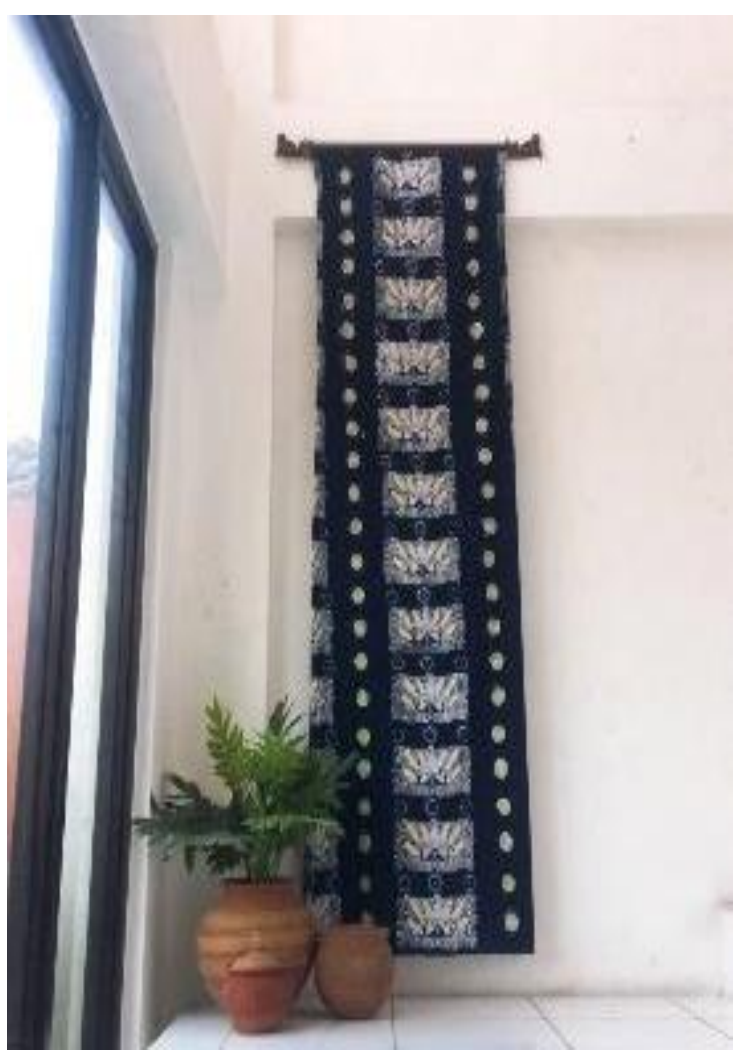

Gambar 26. Area Galeri Rumah Batik Putat Jaya 
Dari hasil realisasi yang telah dilakukan, beberapa perubahan pengembangan desain interior yang diubah meliputi;

1. Area Display \& Gallery, untuk menampilkan karya dari hasil pembuatan batik. Hal ini menjawab kebutuhan mitra dalam menambahkan karya yang dapat ditampilkan sekaligus meningkatkan estetika.

2. Area Workshop, sebagai wadah dalam aktivitas pelatihan masyarakat mengenai proses pembuatan batik, untuk menjawab kebutuhan mitra yang membutuhkan fasilitas ruang khusus untuk aktivitas pelatihan.

3. Area Edukasi, yang berguna sebagai sarana informasi bagi pengunjung mengenai sejarah, dan proses pembuatan batik. Area ini mendukung tujuan mitra yaitu untuk meningkatkan edukasi terhadap masyarakat mengenai literasi batik.

4. Area Penerimaan Tamu, untuk menjawab kebutuhan mitra dalam aktivitas penerimaan tamu-tamu penting.

\section{Proses Serah Terima}

Hasil desain yang telah direalisasikan, diuji coba dan dievaluasi oleh pengguna dan dosen pembimbing. Hasil yang telah direalisasikan mendapatkan respon yang positif dari pengguna, karena dinilai telah berhasil menjawab kebutuhan dari pengguna.

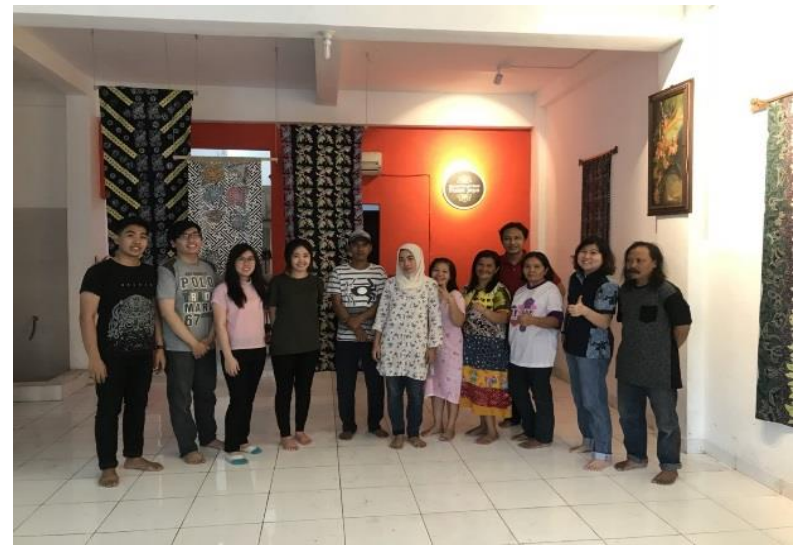

Gambar 27. Serah terima bersama owner Rumah Batik Putat Jaya

\section{KESIMPULAN}

Perancangan interior Rumah Batik Putat Jaya di Surabaya dengan konsep Fun, telah menciptakan suasana yang dapat meningkatkan kualitas di dalam melakukan aktivitas pelatihan di rumah batik. Kegiatan pengembangan desain berhasil memberi pengaruh positif terhadap fasilitas Batik Putat Jaya, yang terindikasi dari meningkatnya aktivitas kunjungan oleh masyarakat sekitar. Hasil dari pengembangan ini diharapkan dapat memicu terbentuknya komunitas batik yang lebih aktif dan berdampak bagi sekitarnya, serta meningkatkan minat dan perhatian turis, baik dalam negeri maupun luar negeri terhadap batik.

\section{DAFTAR PUSTAKA}

Amirah, A. (2015). Cultural, Social, and Economic Perspectives in Making a Criminal Policy (Dolly Prostitituion). Universitas Indonesia. Jakarta.

Carmona, et al. 2008. Public space: the management dimension. New York: Routledge, Taylor \& Francis group

Harjendro, Nugroho. (2004). Galeri Seni Rupa Kontemporer di Yogyakarta. Yogyakarta: Universitas Gadjah Mada

Hermawan, K. (2008). Arti komunitas. Jakarta: Gramedia.

Hwa, L.C., Leow, J., Lau, J. Ho, A., Yoing, C.H. (2016). Design thinking the guidebook. Bhutan: Royal Civil Service Commission.

Retnaningsih, H. (2014). Dampak Sosial Penutupan Lokalisasi Dolly.Pusat Pengkajian, Pengolahan Data dan Informasi (P3DI) Sekretariat Jenderal DPR RI. Jakarta.

Tran, N. (n.d.). Design thinking playbook for changemanagement in $k 12$ schools. Design Tech High School.

http://ibrary.binus.ac.id/eColls/eThesisdoc/Bab2/201 4-2-00398-DI\%20Bab2001.pdf

http://eprints.unsri.ac.id/5356/3/BAB_2.pdf 